\title{
MicroRNA-126 regulates the expression of inflammation- related genes in vascular smooth muscle cells of diabetic rats
}

\author{
Haoyu Dong ${ }^{1}$, Yan Li ${ }^{1}$, Huwei Shen ${ }^{1}$, Hongjuan Cheng ${ }^{2 *}$ \\ ${ }^{1}$ Department of Endocrinology, Heping Hospital, Changzhi Medical College, ${ }^{2}$ Changzhi Medical College, Changzhi, Shanxi, \\ China \\ *For correspondence: Email: Candelariaaces@yahoo.com; Tel: 0086-15603450210
}

\begin{abstract}
Purpose: To investigate the regulatory role of miR-126 in inflammation-associated gene expression in vascular smooth muscle (VSMCs) cells of diabetic rats.

Methods: Diabetes was induced in rats by intraperitoneal injection of streptozocin (STZ) at a dose of 50 $\mathrm{mg} / \mathrm{kg}$. VSMCs were isolated from the aortic intimal-medial layers of the rats by a standard protocol. Expression of miR-126 was determined by quantitative real-time polymerase chain reaction (qRT-PCR) and western blotting. Transfection was performed with Lipofectamine 2000 reagent.

Results: Expression of miR-126 was significantly $(p<0.05)$ downregulated in the VSMCs of diabetic rats. Similarly, expressions of SOD, APX and CAT were downregulated, while those of COX, LOX and NOS were significantly upregulated in VSMCs. However, transfection-induced miR-126 overexpression in the VSMCs of diabetic rats led to significant $(p<0.05)$ upregulation of SOD, CAT, APX and downregulation of COX, LOX and NOS. TargetScan analysis revealed that miR-126 exerted these effects by targeting SIRT1 gene. Furthermore, qRT-PCR and western blotting revealed that miR-126 overexpression in diabetic VMSCs caused significant $(p<0.05)$ upregulation of the expression of SIRT1.

Conclusion: The results indicate that miR-126 regulates the expression of inflammation-related genes by targeting SIRT-1 genes in vascular smooth muscle cells of diabetic rats. Thus, miR-126 may be beneficial in the management of diabetes.
\end{abstract}

Keywords: Diabetes, Inflammation, Genes, microRNA, vascular smooth muscle cells

\begin{abstract}
This is an Open Access article that uses a funding model which does not charge readers or their institutions for access and distributed under the terms of the Creative Commons Attribution License (http://creativecommons.org/licenses/by/4.0) and the Budapest Open Access Initiative (http://www.budapestopenaccessinitiative.org/read), which permit unrestricted use, distribution, and reproduction in any medium, provided the original work is properly credited.
\end{abstract}

Tropical Journal of Pharmaceutical Research is indexed by Science Citation Index (SciSearch), Scopus, International Pharmaceutical Abstract, Chemical Abstracts, Embase, Index Copernicus, EBSCO, African Index Medicus, JournalSeek, Journal Citation Reports/Science Edition, Directory of Open Access Journals (DOAJ), African Journal Online, Bioline International, Open-J-Gate and Pharmacy Abstracts

\section{INTRODUCTION}

Diabetes is a severe metabolic and pathological condition which results in non-physiological changes in many tissues due mostly to oxidative stress [1]. Factors such as increase in the population of aged people, consumption of energy-rich diets, and sedentary life-styles have led to significant increases in the number of diabetic cases globally [2]. Diabetes has been linked to elevated risk of cardiovascular incidents as a result of vascular inflammation and atherosclerosis [3]. Diabetic complications are also associated with upregulated expressions of 
inflammatory cytokines and chemokines [4]. Although it is well reported that inflammationrelated gene expression contributes to diabetic complications, there is hardly any information on the regulation of inflammatory gene expression in this process [5].

MicroRNAs are small non-coding RNA molecules which participate in a wide array of biological functions. They regulate the expressions of most of the genes, and have been implicated in the development of several diseases and disorders [6]. Some microRNAs have also been reported to exhibit aberrant expressions in diabetics, thus making them important targets for the treatment of diabetes $[7,8]$. In the present study, the expression of miR-126 was investigated in the smooth muscle cells of diabetic rats, and its effects on the expression of inflammation-related genes were also evaluated.

\section{EXPERIMENTAL}

\section{Induction of diabetes}

Adult Sprague-Dawley rats $(200 \pm 14 \mathrm{~g})$ were used for induction of diabetes. Diabetes was induced in overnight-fasted rats by intraperitoneal injection of STZ $(50 \mathrm{mg} / \mathrm{kg}$ body weight, $1 \mathrm{ml} / \mathrm{rat})$ in citrate buffer $(0.01 \mathrm{M}, \mathrm{pH} 4.5)$. Rats in the control group were given citrate buffer alone via the same route. The study was approved by the animal ethics committee of Heping Hospital, Changzhi Medical College (approval no. ANM/60A of 2017).

\section{Cell cultures}

Vascular smooth muscle cells (VSMCs) were derived from the aortic intimal-medial layers of diabetic and normal rats as demonstrated earlier [9]. The VSMCs were subjected to phenol redfree M199 treatment containing fetal calf serum for $48 \mathrm{~h}$. Finally, the cells were synchronised in media containing FCS $(0.4 \%)$ for $24 \mathrm{~h}$.

\section{Quantitative real-time polymerase chain reaction (qRT-PCR)}

Total RNA was isolated from the tissues with Trizol reagent and then transcribed into cDNA using RevertAid cDNA synthesis kit. The relative expression was determined by qRT-PCR [10].

\section{Transfection}

When the VSMCs reached $80 \%$ confluence, they were transfected with miR-NC and miR-126 mimics (10 pmol, Shanghai GenePharma), with the help of Lipofectamine 2000 (Invitrogen) as per manufacturer's guidelines [11].

\section{Western blot analysis}

The VSMCs were lysed in lysis buffer and their protein concentrations were determined with Bradford method. Protein expression was measured by western blotting as described previously [12].

\section{Statistical analysis}

Data are shown as mean \pm SD. Statistical analysis was done using Students $t$-test with GraphPad prism 7 software. Values of $p<0.05$ were assumed indicative of significant difference.

\section{RESULTS}

\section{Expression of miR-126 was downregulated in VSMCs}

The expression of miR-126 was significantly downregulated in VSMCs from diabetic rats, when compared to VSMCs from normal control rats $(p<0.05)$. The expression of miR-126 was 5.5-fold lower in VSMCs from the diabetic rats, when compared to the control.

\section{Expression of inflammation-related genes in VSMCs}

The results showed that the expressions of the genes for SOD, CAT and APX were significantly downregulated in the VSMCs from diabetic rats, relative to VSMCs from the normal rats $(p<0.05$, Figure $1 \mathrm{~A}-\mathrm{C})$. The expressions of SOD, CAT and APX were 4.3-, 6.5- and 3.8-fold lower in VSMCs from the diabetic rats than those in VSMCs from the normal rats. These results were further confirmed by the results of western blotting (Figure $1 \mathrm{D}$ ). Similarly, the expression of NOS was significantly $(p<0.05)$ upregulated (5.55-fold) in the VSMCs from diabetic rats when compared to the VSMCs from normal rats (Figure $2 \mathrm{~A}-\mathrm{C}$ ). Similar trends were observed in the expressions of NOS, COX and LOX, as revealed from western blotting (Figure $2 \mathrm{D}$ ).

\section{Overexpression of miR-126 inhibited the expressions of inflammatory genes}

To find out the effect of miR-26 on the expressions of inflammatory genes, VSMCs from the diabetic rats were transfected with miR-NC and miR-126 mimics, and the overexpression of miR-126 was assessed with qRT-PCR (Figure 3 A). The results of qRT-PCR and western blotting showed that the overexpression of miR-126 
significantly downregulated the expressions of the antioxidant enzymes SOD, CAT and APX (Figure $3 \mathrm{~B}-\mathrm{E}$ ), and upregulated the expressions of NOS, COX and LOX as indicated QRT-PCR (Figure $4 \mathrm{~A}-\mathrm{C}$ ) as well as western blot analysis (Figure $4 \mathrm{D}$ ).

\section{MiR-126 exerted its effects by targeting SIRT-} 1

Using TargetScan analysis, SIRT-1 was found to be the potential target of miR-126. This was further confirmed by analysis of the expression of SIRT-1. The results revealed that SIRT-1 expression was downregulated in diabetic VSMCs. However, overexpression of miR-126in diabetic VSMCs caused significant upregulation of the expression of SIRT-1 (Figures $5 \mathrm{~A}-\mathrm{D}$ ).
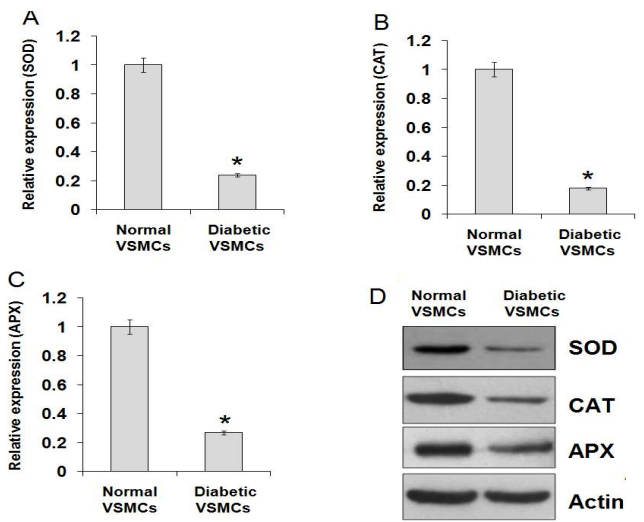

Figure 1: Expressions of (A) SOD, (B) CAT and (C) APX in VSMCs of normal and diabetic, as determined by quantitative RT-PCR analysis, (D) Expressions of SOD, CAT and APX in VSMCs of normal and diabetic rats, as determined by western blot analysis. Values are presented as mean $\pm \mathrm{SD}\left(\mathrm{n}=3,{ }^{*} p<0.05\right)$
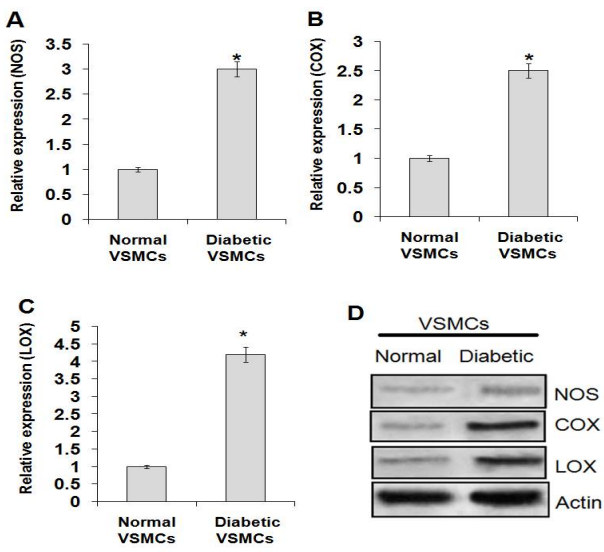

Figure 2: Expressions of (A) NOS, (B) COX, and (C) LOX in VSMCs of normal and diabetic rats, as determined by quantitative RT-PCR analysis, (D) Expressions of NOS, COX and LOX in VSMCs of normal and diabetic rats, as determined by western blot analysis. Values are presented as mean $\pm \mathrm{SD}(\mathrm{n}=$ $\left.3,{ }^{*} p<0.05\right)$
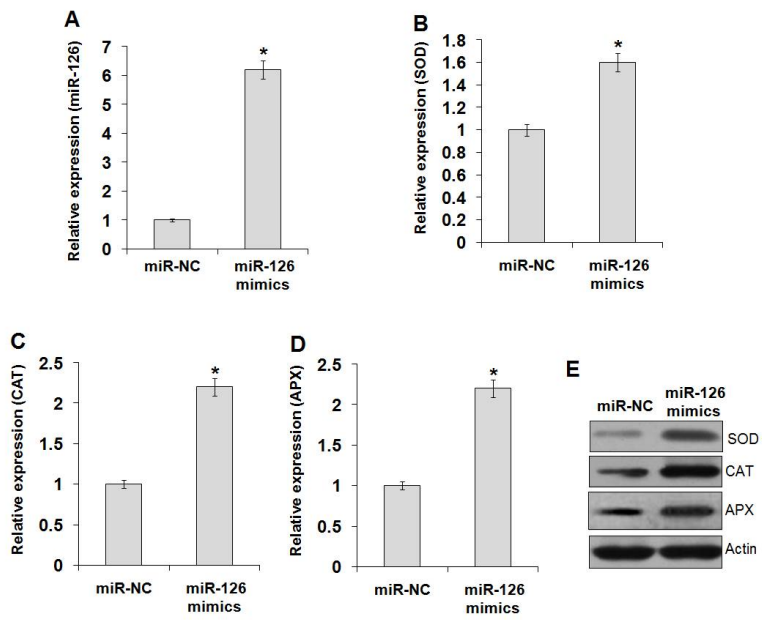

Figure 3: (A) Overexpression of miR-126 in VSMCs of diabetic rats Effect of miR-126 overexpression on the expressions of (B) SOD, (C) CAT and (D) APX as determined by qRT-PCR analysis, (E) Effect of miR126 on the expressions of SOD, CAT and APX, as determined by western blot analysis. Values are presented as mean $\pm \mathrm{SD}\left(\mathrm{n}=3,{ }^{\star} p<0.05\right)$
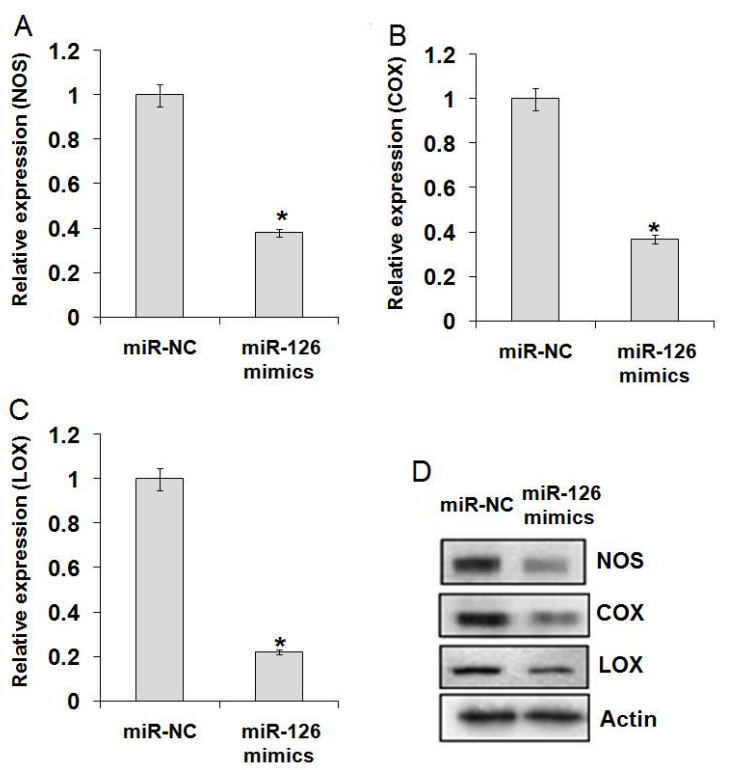

Figure 4: Effect of miR-126 on the expressions of $(A)$ NOS, (B) COX and (C) LOX as determined by qRTPCR analysis, (D) Effect of miR-126 on the expression of NOS, COX, LOX, as determined by western blot analysis. The experiments were performed thrice and he results are depicted as mean $\pm \mathrm{SD}\left(\mathrm{n}=3,{ }^{*} p<\right.$ 0.05)

\section{DISCUSSION}

Diabetes is a severe metabolic disease, and it is well established that oxidative stress is one of main contributors to the onset of diabetic complications [13]. Increased oxidative stress in diabetes is due to accretion of free radicals and/or compromised antioxidant defence 
responses [14]. Oxidative stress either leads to adaptation or cell injury, resulting in damage to DNA, lipids and proteins, accumulation of damaged molecules and disruption of cellular homeostasis [15]. Moreover, although it is known that inflammation-related gene expression contributes to diabetic complications, there is hardly any information on the regulation of antioxidant and inflammatory gene expression in diabetes [16].

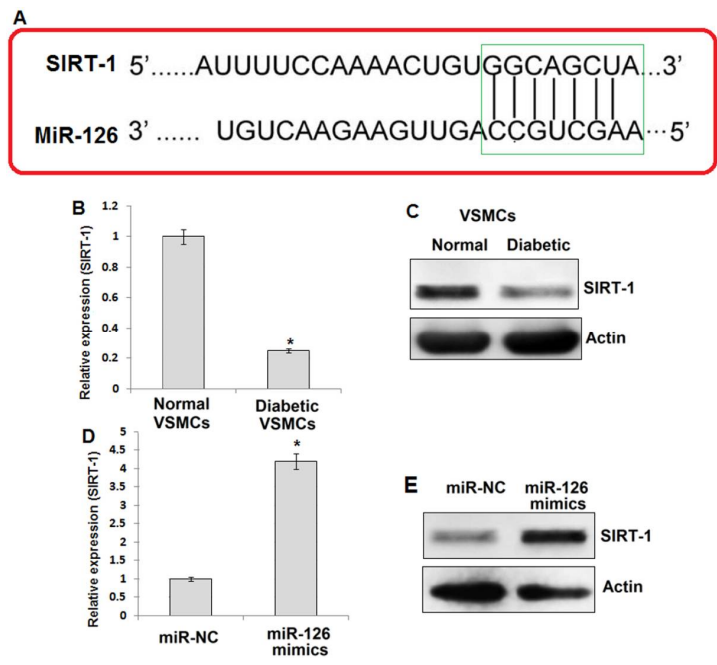

Figure 5: (A) TargetScan depicting miR-126 targets SIRT-1 Expression of miR-126 in VSMCs from diabetic and normal rats, as determined by (B) q RTPCR and (C) western blotting. Expressions of miR-126 in miR-NC and miR-126 mimics transfected VSMCs from diabetic rats as determined by (D) q RT-PCR and (E) western blotting. Values are presented as mean \pm $\mathrm{SD}\left(\mathrm{n}=3,{ }^{*} p<0.05\right)$

MicroRNAs are involved in the development and progression of several diseases and disorders, including, but not limited to cancer and diabetes [17]. In the present investigation, the expression of miR-126 was investigated in the VSMCs of diabetic rats, and it was found that miR-126 expression was significantly downregulated. Diabetes and inflammation are initiated by oxidative stress. Therefore, the expressions of the antioxidant enzymes play a central role in relieving the oxidative stress [18].

In the present study, it was observed that the expressions of SOD, APX and CAT were significantly downregulated in the diabetic VSMCs. The enzymes COX, LOX and NOS are involved in inflammation [19].Their expressions were significantly upregulated in the VSMCs, which implies that they contributed to the inflammation in diabetic VSMCs. To understand the role of miR-126, it was overexpressed in the diabetic VSMCs. The overexpression of miR-126 caused significant enhancement in the gene as well as the protein expressions of the CAT, SOD and APX. Since these enzymes scavenge ROS, they are considered important in alleviating oxidative stress in diabetes and inflammation [19].The enzymes COX, LOX and NOS are involved in the generation of $\mathrm{AA}$, prostaglandins $(\mathrm{PG})$, leukotrienes (LT), and $\mathrm{NO}$ which are crucial mediators of inflammation [20]. In this study, it was observed that overexpression of miR-126 caused significant downregulation of these enzymes. Finally, to investigate the target of miR-126, it was subjected to TargetScan and SIRT-1 was identified as its potential target which was further confirmed by RT-PCR and western blotting.

\section{CONCLUSION}

These results indicate that the expression of miR-126 is significantly downregulated in diabetic VSMCs. Moreover, miR-126 regulates the expression of inflammation-related genes by targeting SIRT-1. Therefore, miR-126 is a potential and important therapeutic target for the management of diabetes.

\section{DECLARATIONS}

\section{Acknowledgement}

The corresponding author acknowledges the Department of Endocrinology, Heping Hospital, Changzhi Medical College for providing some of the facilities.

\section{Conflict of Interest}

No conflict of interest associated with this work.

\section{Contribution of Authors}

The authors declare that this work was done by the authors named in this article and all liabilities pertaining to claims relating to the content of this article will be borne by them.

\section{REFERENCES}

1. American Diabetes Association. Standards of medical care in diabetes-2015 abridged for primary care providers. Clin Diabetes 2015; 33(2): 97.

2. Asmat $U$, Abad $K$, Ismail $K$. Diabetes mellitus and oxidative stress-a concise review. Saudi Pharm J 2016; 24(5): 547-553.

3. Bullon P, Newman HN, Battino M. Obesity, diabetes mellitus, atherosclerosis and chronic periodontitis: a shared pathology via oxidative stress and mitochondrial dysfunction? Periodontology 2014; 64(1): 139-153.

4. Perry RJ, Camporez JP, Kursawe R, Titchenell PM, Zhang D, Perry CJ, Jurczak MJ, Abudukadier A, Han

Trop J Pharm Res, November 2018; 17(11): 2138 
MS, Zhang XM, et al. Hepatic acetyl CoA links adipose tissue inflammation to hepatic insulin resistance and type 2 diabetes. Cell 2015; 160(4): 745-758.

5. Nilsson E, Jansson PA, Perfilyev A, Volkov $P$, Pedersen $M$, Svensson $M K$, Poulsen $P$, Ribel-Madsen $R$, Pedersen NL, Almgren $P$, et al. Altered DNA methylation and differential expression of genes influencing metabolism and inflammation in adipose tissue from subjects with type 2 diabetes. Diabetes 2014; 63(9): 2962-2976.

6. Vidigal JA, Ventura A. The biological functions of miRNAs: lessons from in vivo studies. Trend Cell Biol 2015; 25(3): 137-147.

7. Kurtz CL, Peck BC, Fannin EE, Beysen C, Miao J, Landstreet SR, Ding S, Turaga V, Lund PK, Turner S, Biddinger SB. MicroRNA-29 fine-tunes the expression of key FOXA2-activated lipid metabolism genes and is dysregulated in animal models of insulin resistance and diabetes. Diabetes 2014; 63: 2985-2991.

8. Shantikumar S, Caporali A, Emanueli C. Role of microRNAs in diabetes and its cardiovascular complications. Cardiovasc Res 2011; 93(4): 583-593.

9. Law RE, Meehan WP, Xi XP, Graf K, Wuthrich DA, Coats $W$, Faxon D, Hsueh WA. Troglitazone inhibits vascular smooth muscle cell growth and intimal hyperplasia. $J$ Clin Invest 1996; 98(8): 1897-905.

10. Frank $O$, Heim $M$, Jakob $M$, Barbero $A$, Schäfer $D$, Bendik I, Dick W, Heberer M, Martin I. Real-time quantitative RT-PCR analysis of human bone marrow stromal cells during osteogenic differentiation in vitro. $J$ Cell Biochem 2002; 85(4): 737-746.

11. Dalby B, Cates $S$, Harris A, Ohki EC, Tilkins ML, Price PJ, Ciccarone VC. Advanced transfection with Lipofectamine 2000 reagent: primary neurons, siRNA, and high-throughput applications. Methods 2004; 33(2): 95-103.
12. Hossenlopp $P$, Seurin $D$, Segovia-Quinson B, Hardouin $S$, Binoux M. Analysis of serum insulin-like growth factor binding proteins using Western blotting: use of the method for titration of the binding proteins and competitive binding studies. Anal Biochem 1986; 154(1): 138-143.

13. Li D, Wei Y, Wang D, Gao H, Liu K. MicroRNA-26b suppresses the metastasis of non-small cell lung cancer by targeting MIEN1 via NF-KB/MMP-9/VEGF pathways. Biochem Biophys Res Commun 2016; 472(3): 465-470.

14. Hameed I, Masoodi SR, Mir SA, Nabi M, Ghazanfar K, Ganai BA. Type 2 diabetes mellitus: from a metabolic disorder to an inflammatory condition. World $\mathrm{J}$ Diabetes 2015; 6(4): 598-605.

15. Rochette L, Zeller M, Cottin Y, Vergely C. Diabetes, oxidative stress and therapeutic strategies. Biochim Biophys Acta 2014; 1840(9): 2709-2729.

16. Nowotny $K$, Jung $T$, Höhn $A$, Weber $D$, Grune $T$. Advanced glycation end products and oxidative stress in type 2 diabetes mellitus. Biomolecules 2015; 5(1): 194222.

17. Esser N, Legrand-Poels S, Piette J, Scheen AJ, Paquot $N$. Inflammation as a link between obesity, metabolic syndrome and type 2 diabetes. Diabetes Res Clin Pract 2014; 105(2): 141-150.

18. Chen H, Lan HY, Roukos DH, Cho WC. Application of microRNAs in diabetes mellitus. J Endocrinol 2014; 222(1): R1-0.

19. Herz C, Marton MR, Tran HT, Gründemann C, Schell J, Lamy E. Benzyl isothiocyanate but not benzyl nitrile from Brassicales plants dually blocks the COX and LOX pathway in primary human immune cells. J Funct Food 2016; 23: 135-143.

20. Reczek CR, Chandel NS. ROS-dependent signal transduction. Curropin Cell Biol 2015; 33: 8-13. 